\title{
HERÓIS NO ARMÁRIO: HOMENS TRANS* E PESSOAS NÃO BINÁRIAS PRESTADORAS DE CUIDADO*
}

\section{Resumo}

Este artigo centra-se em narrativas de homens trans* e pessoas não binárias acerca das suas práticas de prestação de cuidados nos universos íntimos da amizade, da família e da conjugalidade. Reconhecendo formas de resistência à adversidade através da prestação de auxílio, sugere-se conceptualizar o cuidado enquanto ato heroico. Esta reconceptualização do cuidado revela-se significativa em contextos onde, por razões de transfobia e de crescente precariedade, tanto o Estado social quanto as famílias falham na sua função de proteção. As experiências de pessoas trans* e não binárias constituem uma plataforma política fundamental para repensar sociologicamente os conceitos de cuidado, masculinidade e dissidência corporal no marco da cidadania íntima na Europa do Sul.

Palavras chave: Trans* e não binárias, cuidado, heroicidade, amizade, Europa do Sul.

\section{Abstract}

Heroes in the closet: care provider trans* men and non-binary people

This article is focused on narratives produced by trans* men and non-binary people about their practices of care provision in the intimate worlds of friendship, family and coupledom. Recognizing the resistance against adversity through care provision, it is suggested that care can be considered a heroic act. Such reconceptualization of care is particularly significant in contexts in which, due to transphobia and the increasing precariousness, both the state and families fail in their protective role. The experiences of trans ${ }^{*}$ and non-binary people offer a crucial political platform to sociologically rethink care, masculinity and corporeal dissidence in the framework of intimate citizenship in Southern Europe.

Keywords: Trans* and non-binary people, care, heroism, friendship, Southern Europe.

\section{Resumen}

Héroes en el armario: hombres trans* ${ }^{*}$ personas no binarias prestadoras de cuidado

Este artículo se centra en las narrativas de hombres trans* y personas no binarias acerca de sus prácticas de prestación de cuidados en los universos íntimos de la amistad, la familia y la conyugalidad. Reconociendo prácticas de resistencia a la adversidad a través de la prestación de auxilio, se sugiere conceptualizar el cuidado en cuanto acto heroico. Esta reconceptualización del cuidado se revela como significativa en contextos donde, por

\footnotetext{
* $\quad$ Este artigo resulta de investigação financiada pelo European Research Council no âmbito do 7. Programa-Quadro da União Europeia (FP/2007-2013) / ERC Grant Agreement «INTIMATE - Citizenship, Care and Choice: The Micropolitics of Intimacy in Southern Europe» [338452].

** Centro de Estudos Sociais da Universidade de Coimbra, 3000-995 Coimbra, Portugal. Endereço postal: Colégio de S. Jerónimo, Apartado 3087, 3000-995 Coimbra, Portugal. Endereço eletrónico: cristina@ces.uc.pt
} 
razones de transfobia y de precariedad creciente, tanto el Estado social como las familias fallan en su función de protección. Las experiencias de personas trans* y no binarias constituyen una plataforma política fundamental para repensar sociológicamente los conceptos de cuidado, masculinidad y disidencia corporal en el marco de la ciudadanía íntima en Europa del Sur.

Palabras-clave: Trans* y no binarias, cuidado, heroicidad, amistad, Europa del Sur.

\section{Introdução}

Apesar de mudanças significativas em anos recentes, há um défice de visibilidade das pessoas lésbicas, gays, bissexuais, transgénero, intersexo e queer (LGBTIQ) ao longo da história. Essa falta de visibilidade traduz-se na fraca expressão de representações empoderadoras das pessoas LGBTIQ. Consequentemente, e como reconhecem Myrte Dierckx e Lucas Platero (2018), assiste-se ao domínio de uma narrativa sobre pessoas LGBTIQ que coloca a tónica na vitimização, na violência e nos problemas de saúde, com domínio dos estudos quantitativos sobre bullying, tentativas de suicídio e incidência de depressão. Apesar de centrais para processos de sensibilização sociocultural e mudança jurídica, o enfoque primordial em narrativas sobre violência e vitimização dificulta o reconhecimento de modelos proativos e empoderadores que constituem também a experiência de pessoas LGBTIQ. Este enviesamento na representação sociocultural que confere maior peso à violência e exclusão, silenciando a agência e a capacitação, encontra na população trans* e não binária um poderoso exemplo (Stryker e Whittle 2006; Richards, Bouman e Barker 2017). ${ }^{1}$

Neste artigo, procura-se responder parcialmente a esse défice, colocando no centro o papel de homens trans* e pessoas não binárias enquanto agentes - e não objetos - na prestação de cuidados a outras pessoas. Desta forma, o artigo propõe que viremos do avesso o imaginário dominante em torno das pessoas trans* enquanto vítimas e pessoas com necessidade de cuidados (materiais, emocionais e de saúde, entre outros), para que sejam reconhecidas enquanto elementos fundamentais na rede de prestação de apoio num contexto de crescente precariedade e de retração do Estado Social na Europa do Sul. Esta inversão do paradigma analítico sobre pessoas trans* e não binárias será feita através da atenção ao tema do cuidado, utilizando-o como ponto de partida para propor o cuidado como um ato

Os usos diversos da terminologia no espetro trans* refletem a ampla diversidade de identidades, experiências incorporadas e expressões de género que habitam o próprio conceito. $\mathrm{O}$ recurso ao asterisco visa refletir justamente a diversidade da comunidade trans ${ }^{*}$, permitindo antecipar experiências por nomear, sem ceder à pretensão de imaginar que tudo quanto pode existir já é. Há um porvir contido na designação trans ${ }^{*}$. Acresce que esta escolha conceptual está em consonância com os padrões internacionais mais atualizados sobre esta matéria (Halberstam 2018; Hines et al. 2018). 
heroico no quotidiano e para indagar acerca da cisnormatividade subjacente ao imaginário de herói. Desta feita, as experiências individuais de homens trans* e pessoas não binárias permite-nos reter a importância da transformação sociocultural operada a nível micro, paralelemente aos avanços jurídicos e políticos de pendor macro já amplamente estudados (Cascais 2004; Carneiro 2009; Saleiro 2013; Santos 2013). Por fim, ao articular os conceitos de cuidado e heroicidade, neste artigo, pretende-se consolidar as insuficientes narrativas de influência (Meyer 2006) relativamente a pessoas LGBTIQ, ou seja, contribuir especificamente para uma história que reconhece o impacto da ação de pessoas trans* e não binárias na vida de outras pessoas.

\section{O que faz de um herói um herói?}

A figura do herói tem acompanhado o imaginário cultural produzido em contextos variados, dialogando de forma mais imediata com arenas de produção cultural - destacando-se aqui a banda desenhada, a literatura e o cinema (Shyminsky 2011). As ciências sociais definem heroicidade de formas também diversas e transversais (Kinsella et al. 2017). Um denominador comum parece ser a identificação de um comportamento de pendor altruístico revelador de coragem excecional e proatividade ao serviço de outras pessoas apesar de condições de adversidade (Becker e Eagly 2004).

Inserindo-se no campo mais amplo dos estudos sobre heroicidade, a figura do herói nacional tem sido analisada enquanto parte do discurso que (re)constrói a nação enquanto realidade e mito, definindo-se a partir de valores como a valentia, a determinação e a pujança física (Lobban 2015; Frisk 2018). Por outras palavras, o herói nacional emerge então como uma figura salvífica, que convoca o imaginário da proteção contra um mal maior ou um perigo eminente (Kinsella et al. 2015).

Uma lente de género a partir dos Estudos sobre as Mulheres, Feministas e de Género (EMFG) (Pereira 2017) permite deslindar o papel desempenhado por estes atributos na manutenção do paradigma dominante de masculinidade (Connell 1995; Whitehead e Barrett 2001). Mas, além da associação a atributos culturalmente masculinizados, um aspeto pouco abordado nos estudos sobre heroicidade é o da homogeneidade da figura do herói. Com efeito, apesar de se autoconstituir enquanto elite figurativa de um coletivo - representando alegadamente o melhor que a nação viu nascer -, os heróis nacionais são frequentemente iguais entre si, surpreendentemente homogéneos, de uma forma objetivamente impossível (Lobban 2015). No contexto da Europa do Sul, todos os heróis que não constituem a exceção que confirma a regra, ${ }^{2}$ são homens cisgénero, brancos, jovens, heterosse-

Ocorre citar a construção de Ricardo Quaresma enquanto herói do futebol nacional e o modo complexo como a sua múltipla pertença identitária é silenciada ou realçada pelos discursos cul- 
xuais, com demonstrada força física e psicológica, e sem deficiência ou doença crónica ou mental. Poder-se-ia sugerir que o imaginário em torno do herói é devedor de uma missão eugenista de seleção entre humanos, que assenta na sobreposição capacitista dos estereótipos de beleza e desempenho físico. De acordo com esta linha de argumentação, para cumprir a narrativa que assim o designa, um herói nacional tem de encaixar no estereótipo de herói nacional de forma a cumprir a expetativa. Como tal, com exceção de casos raros - e devidamente assinalados como tal na literatura científica ${ }^{3}$-, a figura de herói nacional é incompatível com a figura de misfit (Garland-Thomson 2011).

Em suma, a representação em torno do herói nacional não acolhe a possibilidade de diversidade que subjaz a uma nação feita de pessoas heterogéneas. Muitas questões poder-se-iam colocar neste momento: como pode a nação aceitar representar-se a partir de uma imagem tão redutora? Em que medida a representação do herói nacional contribui para uma forma excludente de cidadania que remete para um não-lugar tudo o que lhe é externo? Como são os heróis e as heroínas de que não falamos? Onde estão, como se autorrepresentam, quem os silencia? Podemos pensar uma reapropriação diversa da figura heroica, na linha do conceito shero que, de modo autoevidente, coloca a tónica nas heroínas? Haverá espaço para reconhecer as micropolíticas do heroísmo no quotidiano? Que mecanismos operam para que alguns modelos de heroísmo sejam autorizados a representar legitimamente uma comunidade, enquanto outros são descartados como anormais, perigosos, desprestigiantes, estranhos, monstruosos? E onde se encontram os homens trans* e pessoas não binárias nesta encruzilhada entre heroísmo, corpo e diversidade? Em que medida constituem as pessoas trans* e não binárias exemplos de heroísmo?

\section{De vilão (misfit) a herói (cuidador)}

Resumindo, por via do modo como o corpo heroico é construído, pessoas trans* e não binárias parecem estar excluídas da representação do heroísmo. Já Caterina Nirta alertara: «A crescente popularidade das narrativas trans não libertou os seus corpos da acusação de monstruosidade» (Nirta 2018, 136), afastando-os da possibilidade de ascender ao imaginário heroico caracterizado, entre outros atributos, por uma acentuada cisnormatividade. E, no entanto, por via da transfobia dominante, são justamente as pessoas trans ${ }^{*}$ e não binárias que, no quotidiano, enfrentam fortes ameaças à sua integridade (Rodrigues et al. 2017; Saleiro 2017), cometendo microatos de resistência que, por si só, poderiam constituir atos heroicos. Bastaria, para tal, rever o conceito de heroicidade.

turais dominantes. Ver, a propósito, https:/www.dn.pt/desporto/interior/portugues-quando-acerta-cigano-quando-falha-9512342.html?utm_source=Push\&utm_medium=Web Ver, por exemplo, estudos em torno do conceito de supercrip (Schalk 2016). 
A capacidade de prestar auxílio em situações de adversidade constitui um elemento central do que se define por ato heroico. ${ }^{4}$ Na verdade, a origem etimológica de heroicidade decorre da palavra grega heros, que significa protetor ou defensor. Neste artigo, recuperando o significado original da palavra, sugiro que pensemos no cuidado como ato heroico, em especial em contextos onde, por via da crescente precariedade, tanto o Estado quanto as famílias falham na sua função de proteção social. Nesse sentido, na Europa do Sul, a sociedade providência revela-se fortemente ancorada em redes de amizade constituídas, também, por pessoas trans* e não binárias, para quem as relações de amizade representaram muitas vezes a única corda de salvação que permitiu, antes de tudo, sobreviver.

O ponto de partida empírico para este artigo é o projeto INTIMATE: Cidadania, Cuidado e Escolha - As micropolíticas da cidadania íntima na Europa do Sul, financiado pelo European Research Council entre 2014 e 2019 e desenvolvido no Centro de Estudos Sociais da Universidade de Coimbra. No âmbito do INTIMATE foram conduzidos 18 estudos aprofundados em Portugal, Espanha e Itália, recolhendo-se narrativas por parte de 90 participantes que se autodefinem como LGBTQ. Com um enfoque analítico tripartido sobre cidadania, cuidado e escolha, os estudos estruturaram-se em torno dos temas conjugalidade, parentalidade e amizade enquanto eixos fundamentais das práticas de cidadania íntima. Neste artigo, assim como no projeto de pesquisa que o sustém, seguimos de perto a definição de cidadania íntima cunhada por Ken Plummer em 2003:

A cidadania íntima tem que ver com as decisões que as pessoas têm de tomar acerca do controlo (ou não) do seu corpo, sentimentos e relações; do acesso (ou não) a representações, relações, espaços públicos, etc.; e com escolhas de cariz social (ou não) acerca de identidades, experiências de género e experiências eróticas. Não implica um modelo, um padrão, uma forma. (Plummer 2003, 14)

As entrevistas incluídas neste artigo foram realizadas em Lisboa a homens trans* e pessoas não binárias. Todas as pessoas entrevistadas tinham entre os $25 \mathrm{e}$ os 45 anos, e configuravam um quadro de pertença socioeconómica misto que conjugava um elevado nível educacional (todas as pessoas tinham mestrado) com rendimentos mensais inferiores a 500 euros. O método seguido foi o método interpretativo narrativo biográfico (BNIM) (Wengraf 2007). A decisão de incidir esta reflexão na narrativa de homens trans* e pessoas não binárias é política e visa compensar o peso que a feminização do cuidado apresenta na literatura socioló-

Com efeito, a prestação de cuidados em situações-limite tem permitido a criação de heróis contemporâneos, designados invariavelmente no masculino, com exemplos recentes que incluem a campanha que descreve os bombeiros como heróis sem capa (https://www.alvesbandeira.pt/ campanhas/herois-sem-capa/) ou Arnaud Bertrane, o polícia francês que trocou de lugar com uma refém sequestrada (https://www.publico.pt/2018/03/24/mundo/noticia/morreu-o-policia-frances-que-se-ofereceu-para-ser-trocado-por-uma-refem-1807916). 
gica, permitindo estudar a interseção entre masculinidades não normativas e prestação de cuidado.

Acresce mencionar que as entrevistas utilizadas tiveram lugar no estudo sobre a centralidade da amizade para pessoas trans*. Como explica uma das pessoas entrevistadas,

Acho que uma das especificidades da opressão trans é o nosso isolamento. [...] Quando és trans e começas a falar disto podes perder tudo, a tua família, os teus amigos existentes, e é superassustador. E é por isto que faço este esforço por todas as pessoas trans ainda no armário, ou no início da transição, com que me cruzo, para dizer qualquer coisa, «estou aqui». [Mika, não binári@, 30-34 anos]

Este excerto vai ao encontro de resultados em estudos anteriores acerca das relações de amizade enquanto fonte de intimidade e segurança emocional, particularmente importante em contextos de vulnerabilidade decorrente do preconceito (Roseneil e Budgeon 2004; Roseneil 2006). Por esta razão, a amizade configura uma área indispensável de investigação em matéria de cidadania íntima e prestação de cuidado (Roseneil 2004).

Da análise efetuada no estudo sobre o papel da amizade para pessoas trans* resultou evidente a relevância de práticas informais de prestação de cuidados, mais ou menos continuados no tempo, e que envolviam pessoas familiares mas também amigos ou amigas independentemente do seu estatuto trans*, cisgénero ou não binário. Foram então identificados três tipos principais de cuidado que foram designados por: cuidado intersubjetivo; cuidado corpóreo e clínico; e cuidado logístico.

\subsection{Cuidado intersubjetivo}

A intersubjetividade é umas das áreas que envolve a vida do ser humano e pode definir-se como a capacidade de se relacionar. Nas entrevistas, o cuidado intersubjetivo assumiu frequentemente a forma do acolhimento, do ato de não julgar, de colocar as pessoas à vontade, de se solidarizar. Os seguintes excertos são ilustrativos desta componente da prestação de cuidados na vida das pessoas participantes:

Tenho outra amiga que é cis e hétero, mas as pessoas estão sempre a chateá-la com o seu penteado e ela é alcoólica e tem vergonha, mas não tem vergonha comigo. Ela sabe que eu não julgo, são essas coisas que são muito importantes para mim. [...] Sinto que é da minha responsabilidade ajudar como puder. [Mika, não binári@, 30-34 anos] A minha avó foi para o hospital e estava muito mal, hum..., e eu fui lá visitá-la e acho que lhe perguntei se ela queria rezar. Então ela dá-me as mãos e perguntei-lhe se ela queria rezar, porque eu sei que é uma coisa importante para ela. [...] Estivemos a rezar 
o anjo da guarda. Anjo da guarda, minha companhia, guarda-me a mim e à minha avó de noite e de dia. E pronto. E depois ensinou-me outra vez, há muito tempo que já não me lembrava do pai-nosso, pronto, e ficámos só um bocadinho a rezar e depois começa a fazer as coisas e depois às vezes esquece-se e depois lembramo-nos as duas juntas e eu estou lá. [Ricardo, 25-29 anos, não binári@]

Nestes exemplos, o cuidado intersubjetivo incide sobre a capacidade de prestar apoio em situações de vulnerabilidade suspendendo julgamentos de valor. Tal capacidade de não julgar pode ser interpretada como uma aprendizagem decorrente da incorporação de experiências de discriminação e que, em vez de gerar um fechamento face à diversidade, conduz a um posicionamento empático - por exemplo, acolher a amiga com consumos elevados de álcool ou rezar com a avó, não obstante o legado opressor do judaico-cristianismo relativamente a pessoas LGBTIQ (Toldy e Santos 2016).

Através do cuidado intersubjetivo podemos regressar à definição de transgénero proposta por Jack Halberstam que sugere a identidade trans* enquanto forma relacional: «transgénero pode ser considerado um conceito de relacionalidade; descreve não apenas uma identidade mas uma relação entre pessoas, dentro de uma comunidade, ou dentro de laços de intimidade» (Halberstam 2005, 49).

A relacionalidade que um corpo trans* convoca remete então para a ideia de aliança com outras existências precárias a partir de um corpo que é afinal todo um coletivo, um corpo em aliança, como bem aponta Judith Butler (2015). Nessa linha, a relacionalidade enquanto marcador de uma identidade coletiva trans* estende-se ao entendimento do cuidado como prática relacional, uma prática relacional feita de «corpos na rua na luta, o corpo da multitude» (Oliveira 2017, 135), sem vestígio de essencialismo identitário. E, com efeito, esse cuidado-relação envolve agentes que não habitam necessariamente o círculo da intimidade mais próxima, como se verá no caso do cuidado corpóreo e clínico.

\subsection{Cuidado corpóreo e clínico}

Sob a designação cuidado corpóreo e clínico estão agrupadas práticas de apoio a outras pessoas trans* e não binárias relativamente a conhecimentos técnicos sobre corpo, tratamento hormonal e cuidados de saúde variados. Aprender a enfaixar o peito ou a usar maquilhagem que facilite a alteração da expressão de género através de oficinas sobre $d r a g$, por exemplo, são formas de ajuda prestadas por pessoas trans* a outras pessoas trans*. As redes sociais e outras formas de comunicação online são meios citados para a partilha deste tipo de conhecimento enquanto forma de apoio a pessoas que estão no início de um processo de autoidentificação trans*. Paralelamente, a prestação de cuidados a este nível dá-se de forma presencial, e é relatada enquanto forma de ativismo e de resistência ao isolamento social que a transfobia provoca. No campo da saúde, informação acerca 
de profissionais que facilitam um diagnóstico e o acesso ao tratamento hormonal, ou conhecimento detalhado acerca do impacto da medicação na líbido, por exemplo, são áreas de intervenção descritas pelas pessoas entrevistadas:

Esta pessoa estava-me a dizer que na sua região é superdifícil encontrar psis que dessem um diagnóstico para depois obter hormonas, então eu disse-lhe «em XXXX é fácil e rápido, eu tenho um amigo que fez. Posso-te dar o contacto». São essas coisas. Posso perguntar-lhe, «mas conheces outras pessoas trans? Precisas de...?» Qualquer coisa que me diga que precisava, eu podia encontrar. Não sei tudo, mas sei onde procurar informações. $\mathrm{E}$ eu disse «Para qualquer coisa, estou disponível». Isto faço muitas vezes. [Mika, não binári@, 30-34 anos]

O cuidado corpóreo e clínico inclui ainda a prestação de ajuda a profissionais de saúde cujas práticas e afirmações em contexto de consulta traduzem desconhecimento relativamente ao espetro transgénero, mas que, não obstante, demonstram disponibilidade para aprender:

Senti que comecei a ser também um apoio para outras pessoas porque o que uma pessoa faz desde o início é procurar muita informação, hum..., em sítios muito, muito diferentes e muitos tipos de informações diferentes. Hum, um apoio curiosamente que eu sinto que acabo por dar quase sempre é o próprio apoio que se dá aos médicos. Hum, sentindo eles ou não que estão a ser apoiados. [Hugo, trans, 40-44 anos]

Também para estas/es profissionais de saúde, as pessoas trans* constituem fontes de informação fundamentais e insubstituíveis, por terem um conhecimento especializado e aprofundado acerca das experiências que incorporam (Davy 2011; Platero 2014). Como sublinhava Susan Stryker em 2006, reportando-se a temas relacionados com o modo como funcionam os corpos e as representações acerca deles, e com aquilo que conta ou não enquanto conhecimento, «todas estas questões filosóficas têm consequências materiais na qualidade das vidas transgénero» (Stryker 2006, 9). Mais uma vez se aplica a máxima «nada sobre nós sem nós», celebrizada internacionalmente pelo movimento das pessoas com deficiência, revestindo-se da maior importância relativamente a públicos historicamente silenciados.

\subsection{Cuidado logístico}

Aquilo que sugiro designar por cuidado logístico visa em larga medida o apoio na gestão da vida quotidiana. A gestão da vida quotidiana é feita com recurso a redes de apoio constituídas muitas vezes no contexto da amizade, sobretudo junto de pessoas para quem outras redes falham por via da transfobia ou 
outras formas de desresponsabilização social e familiar. Neste âmbito, realça-se o apoio logístico que inclui preparar refeições para outra pessoa, pagar contas em situação de desemprego, cuidar dos animais, arrumar a casa, fazer as compras de supermercado ou levar uma pessoa idosa a uma consulta, entre outros exemplos.

Como o meu colega de casa teve problemas financeiros, paguei tudo [renda, contas] durante seis meses. [...] Ele tinha caído no alcoolismo e estava a separar-se da sua esposa, que é uma amiga minha também. [...] E vi uma pessoa que era..., que tinha muitas dificuldades em sair de casa, que tinha muita ansiedade, fazia crises de pânico [...]. Quando ir às compras é demasiado difícil, eu vou, quer dizer, eu vou. [...] Um dia ele [pausa, suspiro] hum, assustou-me, começava a ter ideias suicidas e pouco depois decidiu entrar voluntariamente no hospital duas semanas e eu tratei do seu trabalho. Ele tem um trabalho independente, fiz o seu trabalho, tratei dos gatos, fiz tudo em casa. [...] Era bastante deprimente, mas ele sabia que podia apoiar-se em mim para cuidar da casa, por exemplo. [Mika, não binári@, 30-34 anos]

Tudo o que foi preciso em termos de levar os meus pais aqui e ali e ajudar, estar presente antes e depois das cirurgias, quer dizer, tudo o que era necessário. [...] No caso dessa minha tia, tenho sido um apoio permanente a vários níveis, desde tratar da medicação, fazer aquelas coisas que quando eu vejo os anúncios de emprego para auxiliar de geriatria perguntam se a pessoa sabe fazer ou se fez ou que aprende a fazer, basicamente essas coisas, organizar medicação, ir à farmácia, e fazer uma coisa aqui e ali, ir com ela ao médico, também a levo à hidroginástica quando ela precisa. [Hugo, trans, 40-44 anos]

Nestes excertos, é notória a importância de conhecimentos adquiridos aquando do processo de socialização e que são em larga medida incompatíveis com o universo da masculinidade dominante, fortemente ancorada na divisão sexual do trabalho doméstico que alimenta o próprio sistema cis-heteropatriarcal. Por outras palavras, as masculinidades dominantes estão afastadas do conhecimento adquirido por via de processos de socialização que atribuem às mulheres cisgénero funções culturalmente naturalizadas na esfera doméstica, com aprendizagens que começam de forma precoce no cuidado aos irmãos e irmãs mais novas, no apoio a tarefas como limpar e cozinhar, e no incentivo à expressão dos afetos.

Mais tarde, ao longo do processo de construção da transmasculinidade, a pressão para cumprir uma expetativa social dominante em torno dos papéis atribuídos aos homens constitui um fator adicional de complexidade nesse percurso. Pontes e Silva refletem acerca dessa complexidade no seu trabalho acerca de homens trans* no contexto brasileiro: «Negociar com a masculinidade, ou seja, produzir um corpo no registro do masculino, envolve, dentre outros fatores, mobilizar valores e códigos de gênero partilhados dentro dos grupos, entre os sujeitos situados no tempo» (Pontes e Silva 2017, 414). No limite, um papel mais ativo na prestação de cuidado poderia colocar entraves ao reconhecimento de uma mascu- 
linidade num sistema cis-heteropatriarcal em que, tradicionalmente, os homens se encontram arredados dessa responsabilidade.

Todos estes fatores concorrem para a riqueza de experiências acerca do cuidado prestado por homens trans ${ }^{*}$ e pessoas não binárias que desafiam a norma em múltiplas frentes.

\section{Transgenderizando o cuidado: notas conclusivas}

Em 2007, Sally Hines publicava o artigo «Transgendering care: Practices of care within transgender communities», um dos primeiros a considerar as práticas de pessoas trans na rede de prestação de cuidados. Centrando-se na relação desenvolvida com associações e a comunidade trans*, o que Hines (2007) defendia então encontra respaldo no trabalho realizado agora no contexto da Europa do Sul.

Neste artigo, incidiu-se sobre aquilo que se pode designar por micropolíticas do heroísmo no quotidiano e, mais especificamente, sobre o estatuto de herói-cuidador, entendido como alguém que presta cuidados fundamentais ao bem-estar de outras pessoas. Como se viu, a figura do herói corresponde frequentemente a homens cisgénero que cumprem o imaginário de masculinidade dominante, conferindo valor sociocultural a elementos como valentia, determinação e pujança física. Um traço comum é a representação dos heróis enquanto figuras transcendentes, por oposição ao ser humano comum. Por outras palavras, os heróis pertencem ao campo da anormalidade e, não obstante, são celebrados pela cultura dominante - encaixam. O outro lado desta narrativa é ocupado por experiências igualmente atípicas mas não celebradas, materializadas em biografias produzidas por corpos dissidentes, que não encaixam (misfits) - os corpos de pessoas trans* ou não binárias prestadoras de cuidado, por exemplo.

Ao reconhecer práticas altruísticas de resistência à adversidade através da prestação de auxílio conquista-se espaço para aceitar o cuidado enquanto ato heroico. A decisão hermenêutica de colocar o cuidado no mesmo plano simbólico da heroicidade revela-se particularmente significativa em contextos onde, por razões de transfobia e de crescente precariedade, tanto o Estado social quanto as famílias falham na sua função de proteção. Cabe, contudo, salientar que esta decisão não visa contribuir para uma visão simplista das pessoas trans* ou não binárias que seriam então posicionadas num de dois polos opostos no espetro que vai de vítima a herói. As experiências relatadas e as vidas vividas são amplamente complexas e dinâmicas, sendo abundantes exemplos de resistência ao lugar de vítima que não passam necessariamente por uma busca de lugar heroico.

Com base nas entrevistas realizadas a homens trans* e pessoas não binárias, foram propostos três tipos de cuidado: cuidado intersubjetivo, cuidado corpóreo e clínico, e o cuidado logístico. As experiências reportadas neste artigo assumem particular relevo na interseção entre estudos transgénero e estudos sobre o cui- 
dado por duas razões fundamentais. Por um lado, o cuidado tem sido desde sempre um conceito central para os Estudos sobre as Mulheres, Feministas e de Género (Portugal 1998; Lister et al. 2007). Passando por temas como a ética do cuidado ou a reivindicação do cuidado enquanto trabalho não remunerado, os EMFG acabaram por contribuir, involuntariamente, para a cristalização da figura da cuidadora enquanto mulher cisgénero, frequentemente dentro de um quadro heteronormativo e reprodutor, falhando em considerar a transformação do tecido íntimo na contemporaneidade (Roseneil 2004). Tal sucede por via da predominância da visibilidade cultural das mulheres que cuidam das crianças (como irmãs, mães e/ou educadoras) para algumas décadas depois (ou em simultâneo) cuidarem das pessoas mais velhas da família (mães, pais, sogras, sogros). Mas a desatenção face a temas trans* dentro dos Estudos sobre as Mulheres, Feministas e de Género tem sido também uma característica reconhecida (Hines et al. 2018) e que importa contrariar. As experiências de homens trans* e pessoas não binárias no que se reporta à prestação de cuidados interrompe esta narrativa dominante produzida a partir de um modelo longitudinal de prestação de cuidados e convida a repensar as ligações tácitas ou explícitas entre género, domesticidade e cuidado.

Por outro lado, ao aproximar a reflexão sobre prestação de cuidados das vivências de pessoas trans e não binárias, esta pesquisa contribui para um novo paradigma de reconhecimento face ao papel de pessoas tradicionalmente descritas como objetos de cuidado e não sujeitos fundamentais na rede de apoio a outras pessoas. Partindo da análise de entrevistas narrativas biográficas, neste artigo, permite-se regressar aos sujeitos trans* enquanto fonte de autoridade simbólica. Allison Rooke lembra a relevância de narrar o self-trans ${ }^{*}$ e de como o resultado decorrente de processos de partilha de história de vida é relacional: «A experiência de uma pessoa converte-se em autoridade através da interação social com outras pessoas» (Rooke 2010, 70). Neste sentido, recupero as palavras de Isaac West, acerca da importância de assumir uma perspetiva afirmativa no que concerne a investigação com e sobre pessoas trans*:

Contrariamente às representações medicalizadas e patologizantes acerca de pessoas trans, nas quais lhes é subtraída agência e se pressupõe que não sejam iguais a quaisquer cidadãos e cidadãs numa dada comunidade, adoto uma abordagem afirmativa, enfatizando os modos como as pessoas trans se movimentam no mundo e constroem vidas significativas. (West 2014, 9)

Com efeito, a ausência de narrativas de influência, em que pessoas trans* são reconhecidas - e se autorreconhecem - enquanto agentes sociais com papel de relevo é um traço predominante nos estudos LGBTIQ. A decisão de adotar uma abordagem afirmativa na análise realizada visou contribuir para colmatar esse défice. Ao longo de toda a pesquisa realizada nos cinco anos do projeto INTI- 
MATE, apenas nos estudos sobre a centralidade da amizade e das redes de cuidado para pessoas trans ${ }^{*}$ foi possível identificar autonarrativas de reconhecimento e valorização do papel da pessoa LGBTIQ, ou seja, colocando no centro da análise a agência individual enquanto geradora de bem-estar e fonte de empoderamento no sentido de autodeterminação e capacitação.

Em Portugal, como nos contextos espanhol e italiano, recolheram-se histórias de cuidado a pessoas idosas, sobretudo familiares (pais, mães, tias, avós), mas também cuidado a outras pessoas trans* e pessoas cisgénero em situação de precariedade laboral, económica e emocional. As histórias de vida que foram partilhadas connosco no contexto português não podem deixar de ser interpretadas à luz de uma Europa do Sul fortemente familista, na qual a rede informal de prestação de cuidados visa colmatar as falhas de um Estado-providência tardio e, mais recentemente, de um Estado social em retração. Entre as entrevistas realizadas, houve também exemplos de auxílio prestado por pessoas trans* a profissionais de saúde que desconheciam muitos dos aspetos importantes para o apoio clínico e/ou psicológico a pessoas trans*.

Mas, paralelamente às narrativas biográficas que se registaram, importa reconhecer as histórias que não se recolheram e que poderiam igualmente conter exemplos de prestação de cuidados em outras frentes, incluindo no apoio a filhos e filhas de pessoas trans* e não binárias, por exemplo. As histórias recolhidas e as que ficaram por contar provam a relevância conceptual e política de continuar o trabalho sobre este tema, colocando a tónica analítica na agência de pessoas trans* e não binárias. Como defende Hines, «a análise de práticas de cuidado transgénero [...] é fundamental para o entendimento sociológico acerca da diversidade de práticas de identidade, intimidade e cuidado em mudança nas sociedades contemporâneas» (Hines 2007, 1).

No ano em que, fruto do trabalho concertado entre agentes políticos, académicos e ativistas (Hines e Santos 2018), Portugal aprovou uma notável lei de identidade de género respeitadora da autodeterminação, as pessoas que participaram neste estudo são representativas de heróis e heroínas no armário do silêncio pela transfobia que caracteriza muitas das nossas práticas políticas e socioculturais. E, também por isso, as experiências de homens trans* e pessoas não binárias constituem uma plataforma política fundamental para repensar sociologicamente os conceitos de cuidado, masculinidade, heroicidade e dissidência corporal no marco da cidadania íntima na Europa do Sul.

\section{Referências bibliográficas}

Becker, Selwyn W, and Alice H. Eagly. 2004. «The heroism of women and men». American Psychologist 59(3): 163-178. DOI: 10.1037/0003-066X.59.3.163

Butler, Judith. 2015. Notes Toward a Performative Theory of Assembly. Cambridge, MA: Harvard University Press. DOI: https://doi.org/10.4159/9780674495548 
Cascais, Fernando (org.). 2004. Indisciplinar a Teoria. Estudos Gays, Lésbicos e Queer. Lisboa: Fenda.

Carneiro, Nuno Santos. 2009. Homossexualidades: Uma Psicologia Entre Ser, Pertencer e Participar. Porto: Livpsic.

Connell, Raewyn W. 1995. Masculinities. Cambridge: Polity.

Davy, Zowie. 2011. Recognizing Transsexuals. Personal, Political and Medicolegal Embodiment. Farnham: Ashgate.

Dierckx, Myrte, e R. Lucas Platero. 2018. «The meaning of trans* in a family context». Critical Social Policy 38 (1): 79-98. DOI: https://doi.org/10.1177/0261018317731953

Frisk, Kristian. 2018. «What Makes a Hero? Theorising the Social Structuring of Heroism». Sociology (April 2018). DOI: https://doi.org/10.1177/0038038518764568

Garland-Thomson, Rosemarie. 2011. «Misfits: A Feminist Materialist Disability Concept». Hypatia 26 (3): 591-609. DOI: https://doi.org/10.1111/j.1527-2001.2011.01206.x

Halberstam, Jack. 2005. In a Queer Time and Place: Transgender Bodies, Subcultural Lives. Nova Iorque: New York University Press.

Halberstam, Jack. 2018. Trans*. A quick and quirky account of gender variability. Oakland, CA: University of California Press.

Hines, Sally 2007. «Transgendering care: Practices of care within transgender communities». Critical Social Policy 27 (4): 462-486. DOI: https://doi.org/10.1177/0261018307081808

Hines, Sally, e Ana Cristina Santos. 2018. «Trans* policy, politics and research: The UK and Portugal». Critical Social Policy 38 (1): 35-56. DOI: https://doi.org/10.1177/02610183177 32880

Hines, Sally, Zowie Davy, Surya Monro, Joz Motmans, Ana Cristina Santos, e Janneke Van Der Ros. 2018. «Introduction to the themed issue: Trans* policy, practice and lived experience within a European context». Critical Social Policy 38 (1): 5-12. DOI: https:// doi.org/10.1177/0261018317732879

Kinsella, Elaine, Timothy Ritchie, e Eric Igou. 2015. «Lay perspectives on the social and psychological functions of heroes». Frontiers in Psychology 6, 130. DOI: https://doi. org/10.3389/fpsyg.2015.00130

Kinsella, Elaine, Timothy D Ritchie, e Eric Igou. 2017. "Attributes and Applications of Heroes: A Brief History of Lay and Academic Perspectives». In Handbook of Heroism and Heroic Leadership, organizado por Scott T. Allison, George R. Goethals, e Roderick M. Kramer, 19-35. Nova Iorque: Routledge.

Lister, Ruth, Fiona Williams, Anneli Anttonen, Jet Bussemaker, Ute Gerhard, Jacqueline Heinen, Stina Johansson, Arnlaug Leira, Birte Siim, e Constanza Tobío. 2007. Gendering Citizenship in Western Europe: new challenges for citizenship research in a cross-national context. Bristol: The Policy Press. DOI: https://doi.org/10.2307/j.ctt9qgzcn

Lobban, Jackie. 2015. «Homogenous Heroes: selective memory and exclusive myth». History in the Making 4 (1): 44-53.

Meyer, David S. 2006. «Claiming credit: stories of movement influence as outcomes». Mobilization 11 (3): 281-298. Disponível em http://mobilizationjournal.org/doi/abs/ 10.17813/maiq.11.3.952k5670640t253u

Nirta, Caterina 2018. Marginal Bodies, Trans Utopias. Abingdon: Routledge.

Oliveira, João Manuel. 2017. «Trânsitos de Género: leituras queer/trans* da potência do rizoma género». In Géneros e Sexualidades: Interseções e Tangentes, organizado por João Manuel de Oliveira e Lígia Amâncio, 115-138. Lisboa: Centro de Investigação e de Intervenção Social (CIS-IUL).

Pereira, Maria do Mar. 2017. Power, Knowledge and Feminist Scholarship. An Ethnography of Academia. Londres: Routledge. DOI: https://doi.org/10.4324/9781315692623 
Platero, R. Lucas. 2014. Trans*sexualidades: Acompañamiento, factores de salud y recursos educativos. Barcelona: Bellaterra.

Plummer, Ken. 2003. Intimate citizenship: Private discussions and public dialogues. Seattle e Londres: University of Toronto Press.

Pontes, Júlia Clara, e Cristiane Gonçalves da Silva. 2017. «Cisnormatividade e passabilidade: deslocamentos e diferenças nas narrativas de pessoas trans», Periódicus 1 (8): 396-417. DOI: https://doi.org/10.9771/peri.v1i8.23211

Portugal, Sílvia. 1998. «Women, Childcare and Social Networks». In Shifting Bonds, Shifting Bounds. Women, Mobility and Citizenship in Europe, organizado por Virgínia Ferreira, Teresa Tavares e Sílvia Portugal, 345-355. Oeiras: Celta.

Richards, Christina, Walter Pierre Bouman, e Meg-Jon Barker. 2017. Genderqueer and Non-binary Genders. Londres: Palgrave. DOI: https://doi.org/10.1057/978-1-137-51053-2

Rodrigues, Liliana, Nuno Santos Carneiro, e Conceição Nogueira. 2017. «Violência transfóbica: aproximações críticas e horizontes de resistência». In Intervenção psicológica e social com vítimas. Vol. 2 - Adultos, organizado por Sofia Neves, 167-192. Coimbra: Almedina.

Rooke, Allison, 2010. «Telling Trans Stories: (Un)doing the science of sex». In Transgender Identities. Towards a Social Analysis of Gender Diversity, organizado por Sally Hines, e Tam Sanger, 64-83. Londres: Routledge.

Roseneil, Sasha, e Shelley Budgeon. 2004. "Cultures of intimacy and care beyond the 'family': personal life and social change in the early twenty-first century». Current Sociology 52 (2): 135-159. DOI: https://doi.org/10.1177/0011392104041798

Roseneil, Sasha. 2004. «Why we should Care about Friends: An Argument for Queering the Care Imaginary in Social Policy». Social Policy and Society 3 (4): 409-419. DOI: https:// doi.org/10.1017/S1474746404002039

Roseneil, Sasha. 2006. «Viver e amar para lá da heteronorma: Uma análise queer das relações pessoais no século XXI». Revista Crítica de Ciências Sociais 76: 33-51. DOI: https:// doi.org/10.4000/rccs.818

Saleiro, Sandra Palma. 2013. Trans Géneros: Uma abordagem sociológica da diversidade de género. Tese de Doutoramento em Sociologia. Lisboa: ISCTE-IUL.

Saleiro, Sandra Palma. 2017. «Diversidade de género na infância e educação: Contributos para uma escola sensível ao (trans)género». Ex æquo 36: 149-165. DOI: https://doi. org/10.22355/exaequo.2017.36.09

Santos, Ana Cristina. 2013. Social Movements and Sexual Citizenship in Southern Europe. Basingstoke: Palgrave. DOI: https://doi.org/10.1057/9781137296405

Schalk, Sami. 2016. «Reevaluating the Supercrip». Journal of Literary E Cultural Disability Studies, 10 (1): 71-86. DOI: https://doi.org/10.3828/jlcds.2016.5

Shyminsky, Neil. 2011. "'Gay' sidekicks: queer anxiety and the narrative straightening of the superhero». Men and Masculinities 14 (3): 288-308. DOI: https://doi.org/10.1177/109 7184X10368787

Stryker, Susan. 2006. «(de)Subjugated knowledges: an introduction to transgender studies». In The Transgender Studies Reader, organizado por Susan Stryker e Stephen Whittle, 1-18. Nova Iorque: Routledge.

Stryker, Susan, e Stephen Whittle (orgs). 2006. The Transgender Studies Reader. Nova Iorque: Routledge.

Toldy, Teresa, e Ana Cristina Santos, orgs. 2016. «Religião, género e cidadania sexual», número semitemático da Revista Crítica de Ciências Sociais, 110. Disponível em https:// journals.openedition.org/rccs/6342

Wengraf, Tom. 2007. «Guide to BNIM Biographic-Narrative Interpretive Method: Intervie- 
wing for Life-Histories, Lived Situations and Ongoing Personal Experience». Version 7.11e, 26 November. Disponível em tom@tomwengraf.com.

West, Isaac. 2014. Transforming Citizenships. Transgender Articulations of the Law. Nova Iorque: New York University Press.

Whitehead, Stephen. M., e Frank J. Barrett. 2001. The Masculinities Reader. Cambridge: Polity Press.

Ana Cristina Santos. Socióloga. Doutorada em Estudos de Género pela Universidade de Leeds, Reino Unido, e Mestre em Sociologia pela Universidade de Coimbra, Portugal, é Investigadora no Centro de Estudos Sociais, Universidade de Coimbra, e Honorary Research Fellow no Birkbeck Institute for Social Research, Universidade de Londres. Tem trabalhado em projetos de investigação sobre género, sexualidade, corpo, LGBTQI+, movimentos sociais, cidadania e direitos humanos. Vice-presidente da Sexuality Research Network da Associação Europeia de Sociologia entre 2012 e 2016, é Cocoordenadora desde 2013 do programa de doutoramento internacional Human Rights in Contemporary Societies do Centro de Estudos Sociais da Universidade de Coimbra.

Endereço eletrónico: cristina@ces.uc.pt

Artigo recebido a 3 de agosto de 2018 e aceite para publicação a 25 de setembro de 2018. 
